\title{
Análise da variabilidade genética de Alphitobius diaperinus utilizando marcadores moleculares de DNA
}

\author{
Paulo Roberto Queiroz da Silva ${ }^{1}$ \\ Érica Soares Martins ${ }^{2}$ \\ Lunalva Sallet ${ }^{3}$ \\ Rose Gomes Monnerat ${ }^{4}$
}

\section{Resumo}

Alphitobius diaperinus (Panzer, 1797) é uma espécie cosmopolita originária do continente africano encontrada em grande quantidade em cama de frango, causando problemas sanitários e econômicos, afetando a saúde e o crescimento das aves e atuando também como transmissor de doenças. Indivíduos adultos de A. diaperinus foram coletados aleatoriamente de camas aviárias em três propriedades localizadas nos estados do Paraná, Santa Catarina e Rio Grande do Sul, analisados molecularmente por meio da técnica de RAPD. Para isso, foi adaptada uma metodologia para extração de DNA e testados os iniciadores decaméricos OPA-03, OPA-04, OPA-10, OPA-11 e OPA-13. O protocolo de extração de DNA que foi adaptado produziu fragmentos de DNA para a análise das populações de cascudinho, originárias da região sul do Brasil por RAPD. Foi encontrada alta variabilidade genética entre as populações de cascudinho. Além disso, sugere-se que indivíduos de A. diaperinus ocorrendo no Paraná possam ter se deslocado para os estados de Santa Catarina e Rio Grande do Sul.

Palavras-chave: Alphitobius diaperinus. Coleoptera. RAPD. Identificação molecular.

1 PhD Biologia Animal. Universidade de Brasília - UnB. Professor do curso de Biologia UniCEUB; e-mail: pqsilva@uol.com.br

2 PhD Biologia Molecular. Universidade de Brasília - UnB; e-mail: erica_martins@pop. com.br

3 Doutoranda Biologia Molecular. Universidade de Brasília - UnB

4 PhD Ciências Agrárias. Ecole Nacionale Agronomique de Montpellier. Embrapa Recursos Genéticos e Biotecnologia; e-mail: rose@cenargen. embrapa.br 


\section{Introdução}

Alphitobius diaperinus (PANZER, 1797), conhecido popularmente como cascudinho, é uma espécie cosmopolita originária do continente africano. Essa espécie é comumente encontrada infestando resíduos de produtos úmidos estocados que, provavelmente, migrou para os aviários por trânsito de insumos para as fazendas (WALLACE et al., 1985). Atualmente, encontra-se em grande quantidade em cama de frango, causando problemas sanitários e econômicos, afetando a saúde e o crescimento das aves e atuando também como transmissor de doenças (CHERNAKI et al., 2001).

O inseto infesta os aviários, transmite doenças às aves e afeta seu desenvolvimento quando ingerido juntamente com a ração. A criação em confinamento proporcionou ao cascudinho um hábitat ideal para a sua multiplicação, transformando-o em um problema mundial. Esse inseto alimenta-se de aves em fase final de vida, das carcaças, fezes e ração de aves (LESCHEN; STEELMAN, 1988). É considerado um vetor de patógenos que se localizam tanto na superfície externa quanto no trato digestivo. Seu controle é dificultado pelos hábitos crípticos e pela presença constante das aves nos aviários (VITTORI, 2007). O ciclo biológico do cascudinho está diretamente relacionado à temperatura (CHERNAKI et al., 2001).

Um aspecto importante no controle de pragas é o conhecimento de suas características fenotípicas e genotípicas. Esse conhecimento pode auxiliar no estabelecimento do perfil genético dos insetos e na identificação de marcadores que apontem para populações resistentes a inseticidas ou potencialmente transmissoras de doenças. A técnica de RAPD tem sido muito utilizada na obtenção de informações para a análise genômica, por apresentar características que permitem a obtenção de um grande número de informações para a análise de genomas, de cuja composição pouco se conhece a respeito. Essa técnica emprega a utilização de um único oligonucleotídio de sequência arbitrária, com potencial de reconhecer regiões desconhecidas do DNA alvo (WILLIAMS et al., 1990). Os marcadores RAPD se baseiam na amplificação do DNA, gerando simplicidade e rapidez a baixos custos. Assim, grande quantidade de polimorfismo e segmentos de DNA é obtida em curto espaço de tempo. Para que haja a amplificação de um fragmento RAPD, duas sequências de DNA complementares ao iniciador devem estar a menos de $4 \mathrm{~kb}$ 
e em orientação oposta, para permitir a amplificação pela Taq DNA polimerase (FERREIRA; GRATTAPAGLIA, 1998). Uma característica desse tipo de marcador é o seu comportamento como marcador genético dominante. Lembrando que a dominância, neste caso, não se refere à interação genética entre alelos de um mesmo loco e sim à interpretação relativa entre fenótipo e genótipo (CIAMPI; MAGALHÃES, 2001).

\section{Objetivo}

Estabelecer um protocolo de extração de DNA, obter perfis de marcadores moleculares RAPD e determinar a variabilidade genética entre indivíduos de $A$. diaperinus originários de três estados da região sul do Brasil.

\section{Material e métodos}

\section{Origem dos indivíduos de A. diaperinus}

Indivíduos adultos de $A$. diaperinus foram coletados aleatoriamente de camas aviárias, em três propriedades localizadas nos estados do Paraná, Santa Catarina e Rio Grande do Sul. Após a coleta, os adultos foram mantidos em etanol 100\% a $-20^{\circ} \mathrm{C}$ no laboratório de bactérias entomopatogênicas da Embrapa Recursos Genéticos e Biotecnologia.

\section{Obtenção de ácidos nucleicos}

Para as análises moleculares, o DNA de oito indivíduos adultos de cada amostra de $A$. diaperinus foi extraído a partir de uma adaptação do método previamente estabelecido por Queiroz et al. (2005).

Submeteu-se um indivíduo adulto à maceração e, a seguir, adicionou-se 500 $\mu \mathrm{L}$ de tampão de extração (Tris-HCl 10 mM pH 8, EDTA 1 mM, Triton X-100 0,3\% 
e Proteinase K $120 \mu \mathrm{g} . \mathrm{mL}^{-1}$ ), incubando-se por $30 \mathrm{~min}$. a $65^{\circ} \mathrm{C}$. O homogenato foi centrifugado por $10 \mathrm{~min}$. a $10.000 \mathrm{x} g$ e, o sobrenadante, transferido para um tubo plástico. Adicionou-se $500 \mu \mathrm{L}$ de fenol/clorofórmio/álcool isoamílico (25:24: 1) e as fases foram homogeneizadas em vortex por 30s. O material foi centrifugado por $10 \mathrm{~min}$. a $10.000 \mathrm{x} g$ e a $10^{\circ} \mathrm{C}$. A fase aquosa foi então transferida para um novo tubo plástico, repetindo-se a etapa anteriormente descrita.

O DNA foi precipitado pela adição de $30 \mu \mathrm{L}$ de $\mathrm{NaCl} 5 \mathrm{M}$ e $1 \mathrm{~mL}$ de etanol absoluto, incubando-se por $2 \mathrm{~h} \mathrm{a}-20^{\circ} \mathrm{C}$. Após centrifugação, a $10.000 \mathrm{x} g$ por 10 min a $10^{\circ} \mathrm{C}$, o DNA precipitado foi lavado duas vezes com $500 \mu \mathrm{L}$ de etanol $70 \%$, seco à temperatura ambiente e ressuspenso em TE 0,1 X (Tris- $\mathrm{HCl} 1 \mathrm{mM} \mathrm{pH} \mathrm{8,}$ EDTA $0,1 \mathrm{mM}$ ) e armazenado a $-20^{\circ} \mathrm{C}$. Para as análises de RAPD, utilizou-se o DNA diluído em TE 0,1 X até a concentração de 20 ng. $\mu \mathrm{L}^{-1}$.

\section{Reações de RAPD}

Para os estudos de caracterização molecular, o DNA extraído a partir de oito indivíduos de cada amostra foi utilizado em $30 \mu \mathrm{L}$ de uma reação de RAPD, contendo tampão Tris-HCl 6 mM (pH 8,8), $\mathrm{KCl} 50$ mM, $\mathrm{MgCl}_{2} 2 \mathrm{mM}$, dNTP's (Invitrogen) 0,2 mM, 0,4 $\mu \mathrm{M}$ de um oligonucleotídio de sequência aleatória da Operon Technologies, Inc. (Tabela 1), 2,5 U. $\mu \mathrm{L}^{-1}$ de Taq DNA polimerase (GE Healthcare) e $5 \mu \mathrm{L}$ de DNA (20 ng. $\left.\mu \mathrm{L}^{-1}\right)$.

Tabela 1 - Oligonucleotídios usados nas reações de RAPD.

\begin{tabular}{cc}
\hline Iniciador & Sequência $\left(5^{\prime} \rightarrow 3^{\prime}\right)$ \\
\hline OPA-03 & AGT CAG CCA C \\
OPA-04 & AAT CGG GCT G \\
OPA-10 & GTG ATC GCA G \\
OPA-11 & CAA TCG CCG T \\
OPA-13 & CAG CAC CCA C \\
\hline
\end{tabular}




\section{Obtenção de perfis eletroforéticos}

As amplificações foram efetuadas em termociclador (PTC 100 MJ Research) programado para 45 ciclos, contendo uma etapa inicial de desnaturação de 3 min. a $94^{\circ} \mathrm{C}$. Cada ciclo foi constituído de uma etapa de desnaturação de 1 min a $93^{\circ} \mathrm{C}$, anelamento, por $1 \mathrm{~min}$ a $35^{\circ} \mathrm{C}$ e extensão, por $2 \mathrm{~min}$ a $72^{\circ} \mathrm{C}$. Após os ciclos, foi realizada uma etapa de extensão final de $5 \mathrm{~min}$ a $72^{\circ} \mathrm{C}$. Os produtos de amplificação foram visualizados em gel de agarose 1,5 \% submerso em tampão TBE 1X (Tris-borato $9 \mathrm{mM}$ e EDTA $1 \mathrm{mM}$ ), fotografados e arquivados no sistema Eagleeye. Em todos os géis, marcadores de massa molecular (Ladder 100 bp - GIBCO), foram usados para a determinação do tamanho dos fragmentos amplificados.

\section{Análise dos dados}

As fotos das amplificações realizadas com os iniciadores selecionados foram usadas para a análise do polimorfismo entre os indivíduos de cada amostra. Os fragmentos presentes nos géis foram considerados como marcadores RAPD. Foi gerada então uma matriz de similaridade, levando-se em consideração as relações entre indivíduos, oligonucleotídios e massas moleculares das bandas obtidas com um dado iniciador. Utilizou-se o valor 1 (um) para a presença de um marcador, e 0 (zero) para a ausência. No caso de dúvida, o número 9 (nove) foi usado como padrão. A seguir, a planilha obtida foi submetida a um programa de análise estatística multivariada para a determinação das distâncias genéticas entre os indivíduos. A matriz de similaridade foi obtida por meio do coeficiente de Jaccard, após, o que, por meio da análise por UPGMA, produziu-se um dendrograma que evidenciou o agrupamento dos indivíduos, utilizando-se o programa NTSYS versão 2.02 pc (RHOLF, 1993).

\section{Resultados}

A metodologia de extração de DNA que foi adaptada de Queiroz et al. (2005) produziu perfis eletroforéticos de RAPD para as três amostras de A. diaperinus. A preservação dos indivíduos em etanol, seguida da conservação em baixa 
temperatura, permitiu a extração de DNA em quantidade e em qualidade para as reações de amplificação, utilizando-se os iniciadores OPA-03, OPA-04, OPA-10, OPA-11 e OPA-13. Os cinco oligonucleotídios produziram 54 fragmentos de DNA, com uma média de 10,8 \pm 4,9 fragmentos de RAPD por iniciador (Tabela 2).

Tabela 2 - Número total de fragmentos produzidos por cinco iniciadores de RAPD utilizando-se DNA de A. diaperinus.

\begin{tabular}{cccc}
\hline Iniciador & $\begin{array}{c}\text { Fragmentos } \\
\text { isomórficos }\end{array}$ & $\begin{array}{c}\text { Fragmentos } \\
\text { polimórficos }\end{array}$ & Total de fragmentos \\
\hline OPA-03 & 4 & 7 & 11 \\
OPA-04 & 0 & 19 & 19 \\
OPA-10 & 1 & 8 & 9 \\
OPA-11 & 0 & 9 & 9 \\
OPA-13 & 2 & 4 & 6 \\
Total & 7 & 47 & 54 \\
\hline
\end{tabular}

Observou-se que os iniciadores OPA-04 e OPA-03 produziram o maior número de fragmentos de RAPD (35,2\% e 20,4\%, respectivamente). Em seguida, os oligonucleotídios OPA-10 e OPA-11 com 16,7\%. O iniciador OPA-13 produziu o menor número de fragmentos $(11,1 \%)$.

Os iniciadores OPA-03 e OPA-13 produziram o maior número de fragmentos isomórficos (7,4\% e 3,7\%). O iniciador OPA-10 produziu o menor número de fragmentos isomórficos (1,8\%). Entretanto, os oligonucleotídios OPA-04 e OPA-11 não produziram fragmentos isomórficos.

O iniciador OPA-04 produziu o maior número de fragmentos polimórficos, correspondendo a 35,2\%. O oligonucleotídio OPA-13 produziu o menor número de fragmentos polimórficos $(7,4 \%)$.

Os diferentes iniciadores de RAPD produziram diferentes padrões eletroforéticos (Figura 1).

Com o oligonucleotídio OPA-03, observou-se polimorfismo de fragmentos entre os indivíduos das amostras de A. diaperinus na faixa de $200 \mathrm{pb}$ a $1200 \mathrm{pb}$. Com o emprego desse iniciador de RAPD, não foi possível identificar um padrão 
de fragmentos específico para qualquer uma das amostras de cascudinho provenientes da região sul do Brasil.

Figura 1 - Perfis de marcadores moleculares de RAPD de indivíduos de três amostras de A. diaperinus, obtidos a partir do uso de cinco iniciadores de RAPD. A letra M representa o marcador 100 pb ladder. Os números de 1 a 8, amostras originárias de Santa Catarina; 9 a 16, Paraná; 17 a 24, Rio Grande do Sul.

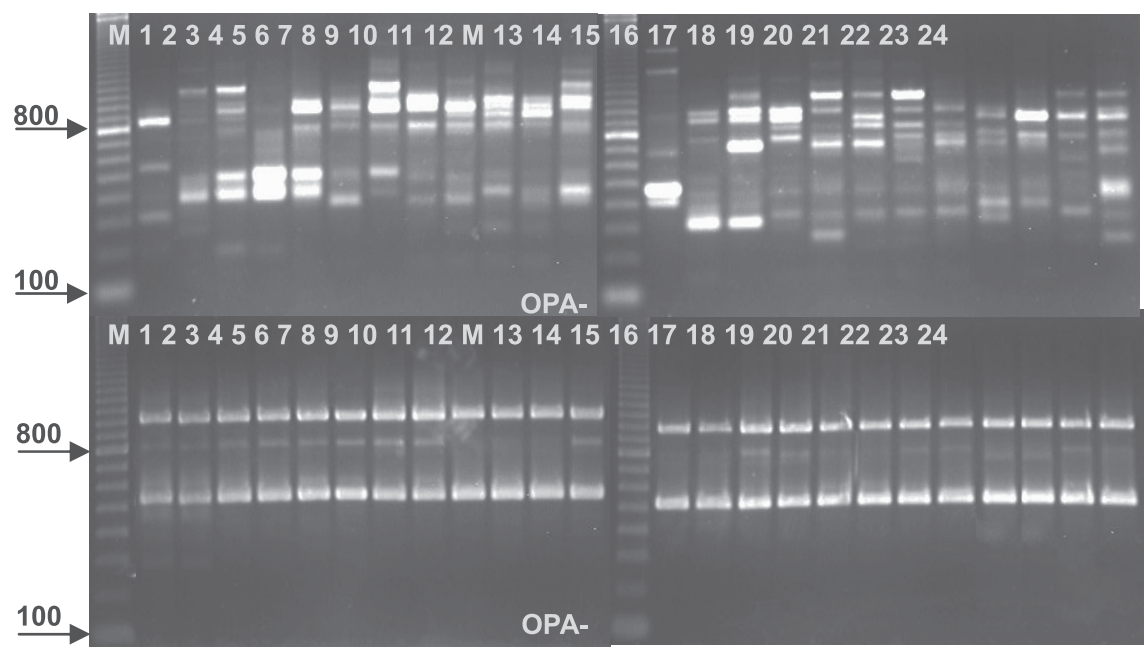

Contudo, o iniciador OPA-13 produziu fragmentos de DNA específicos de 520 pb e 1050 pb em todos os indivíduos das três amostras de A. diaperinus analisadas nesse estudo.

O polimorfismo produzido pelos indivíduos das três amostras foi então utilizado para a determinação da matriz de similaridade pelo programa NTSYS (Figura 2).

$\mathrm{Na}$ análise da matriz de similaridade, observou-se que os indivíduos RS1 e PR8 apresentaram a maior porcentagem de similaridade com 83,33\% e os indivíduos PR8 e PR6 com porcentagem de similaridade de 73,68\%.

Para os indivíduos SC8 e SC1, observou-se a menor porcentagem de similaridade com 14,29\% e os indivíduos SC7 e SC1 com 17,24\%. 
Figura 2 - Matriz de similaridade genética entre os indivíduos A. diaperinus pertencentes à amostras coletadas na Região Sul do Brasil. As letras indicam: PR, amostras provenientes do Paraná; RS, Rio Grande do Sul; SC, amostras originárias de Santa Catarina. Os números indicam o número de indivíduos de cada amostra. Nos retângulos estão destacadas as maiores e menores distâncias genéticas.

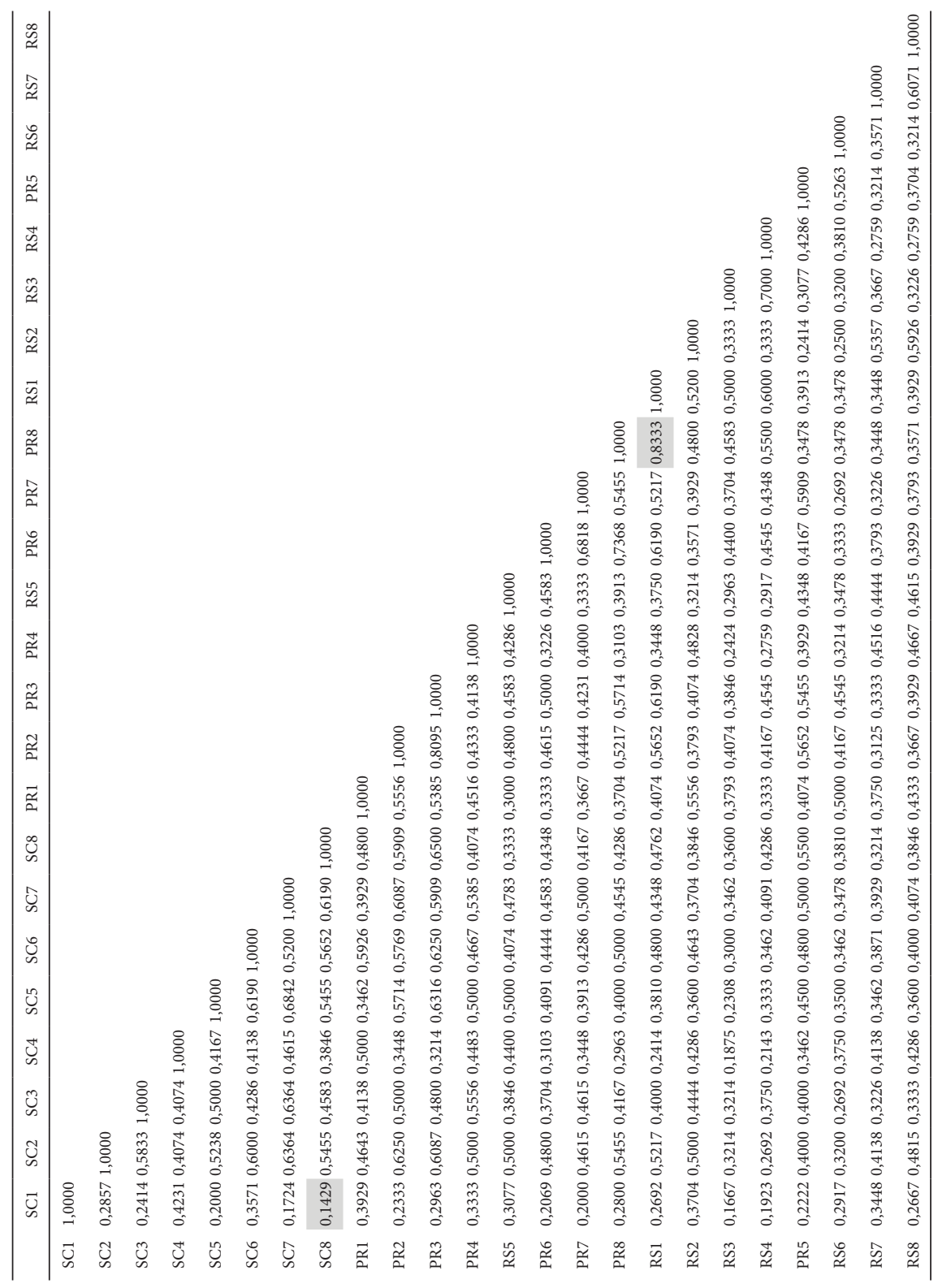


Em seguida, foram avaliadas as porcentagens de similaridade entre as amostras de A. diaperinus coletadas nos três estados da região sul do Brasil (Tabela 3).

Tabela 3 - Índices de similaridade intra e interamostrais entre indivíduos de A. diaperinus coletados em três localidades da região sul do Brasil.

\begin{tabular}{cccc}
\hline \multirow{2}{*}{ Amostra } & \multicolumn{3}{c}{ Índice de similaridade (\%) } \\
\cline { 2 - 4 } & Mínimo & Máximo & Diferença \\
\hline Santa Catarina & 14,29 & 68,42 & 54,13 \\
\hline Santa Catarina x Paraná & 20,00 & 65,00 & 45,00 \\
Santa Catarina x Rio Grande do Sul & 16,67 & 55,00 & 38,33 \\
\hline Paraná & 30,00 & 73,68 & 43,68 \\
Paraná x Rio Grande do Sul & 32,14 & 83,33 & 51,19 \\
Rio Grande do Sul & 27,59 & 70,00 & 42,41
\end{tabular}

Observou-se que a maior variação das porcentagens de similaridade ficou entre os indivíduos da amostra de Santa Catarina (54,13\%) e, em seguida, entre os indivíduos coletados no Paraná e no Rio Grande do Sul (51,19\%).

A menor variação observada ficou entre os indivíduos da amostra proveniente do Rio Grande do Sul com 42,41\%.

A seguir, os dados binários correspondentes aos vários indivíduos das três amostras provenientes da Região Sul do Brasil foram utilizados para a determinação de um dendrograma para o estabelecimento das relações filogenéticas entre as populações de A. diaperinus (Figura 3).

No dendrograma, foram identificados dois grupos principais (A e B) com $37 \%$ de similaridade. Dentro do grupo B, foram identificados dois subgrupos (B1 e B2) com 30\% de similaridade.

Nos agrupamentos, foi encontrada uma possível relação entre as amostras coletadas em Santa Catarina e no Rio Grande do Sul com a população do Paraná. No subgrupo B1, foram encontrados os indivíduos coletados no Paraná e no Rio Grande do Sul com 47\% de similaridade. No subgrupo B2, foram encontrados indivíduos provenientes de coletas no Paraná e em santa Catarina com similaridade de $42 \%$. 
Figura 3 - Dendrograma construído a partir dos marcadores de RAPD, obtidos de três amostras de A. diaperinus. As letras indicam: PR, amostras provenientes do Paraná; RS, Rio Grande do Sul; SC, amostras originárias de Santa Catarina. Os números acompanhando os códigos indicam o número dos indivíduos de cada população.

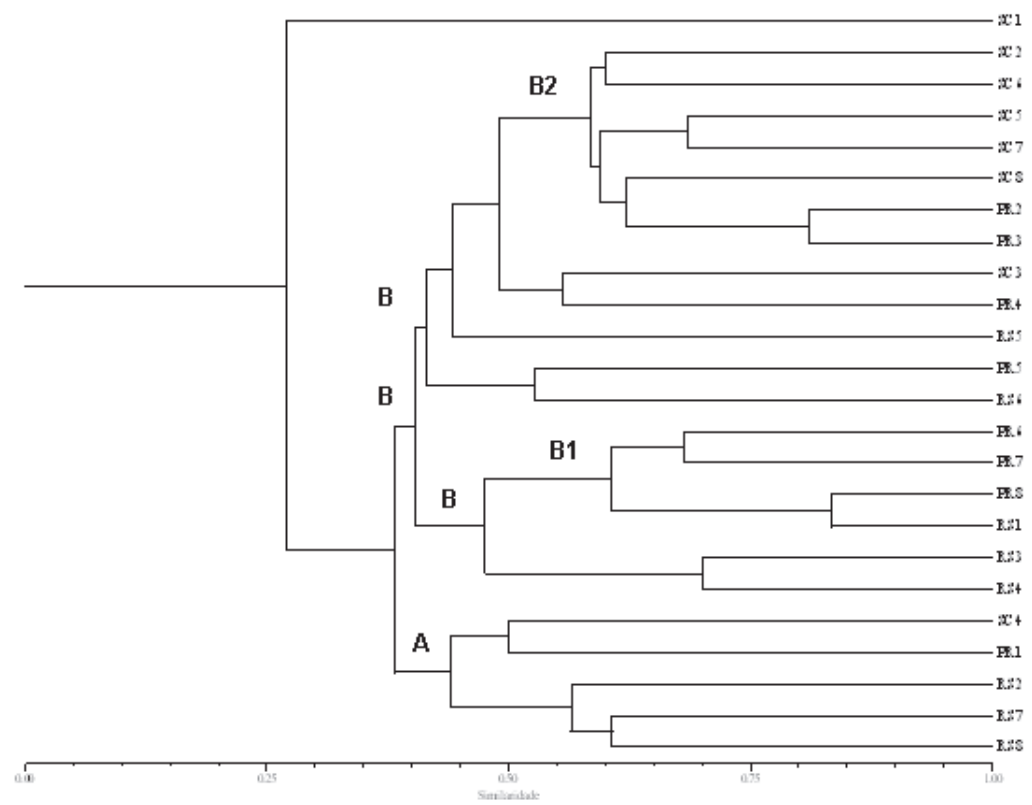

Além disso, em cada ramo estabelecido no dendrograma, foi possível identificar, sempre, indivíduos originários do estado do Paraná. Por exemplo, no subgrupo B1a, foram encontrados dois indivíduos provenientes do Paraná com 62\% de similaridade com dois indivíduos coletados no Rio Grande do Sul. Nesse mesmo subgrupo, um indivíduo do Paraná apresentou 83\% de similaridade com um indivíduo originário do Rio Grande do Sul. No subgrupo B2a, foram encontrados dois indivíduos coletados no Paraná apresentando 59\% de similaridade com seis indivíduos coletados em Santa Catarina.

A análise do dendrograma revelou uma elevada variabilidade genética entre os indivíduos das três populações, com valores de similaridade inferiores a $84 \%$. A faixa principal de similaridade entre os indivíduos ficou entre 38\% e 70\%. 
A análise de variância molecular (AMOVA) das três amostras de A. diaperinus, quando avaliadas conjuntamente, ou seja, como um grupo único, revelou que a fonte de variação era de 94,26\% dentro das populações e apenas 5,74\% entre as populações. Quando as amostras foram comparadas individualmente umas com as outras, as análises de AMOVA não revelaram uma estrutura genética definida para essas amostras.

\section{Discussão}

Em virtude de seu amplo espectro de uso, a técnica de RAPD tem sido aplicada em diferentes níveis de estudo na caracterização molecular, tanto de populações de insetos-praga quanto das possíveis espécies relacionadas.

Queiroz et al. (2004) analisaram a variabilidade de A. grandis empregando essa mesma estratégia molecular. Os resultados obtidos revelaram a variabilidade genética existente dentro de uma população mantida em criação.

Pela determinação da matriz de similaridade, foi possível observar uma elevada variabilidade genética dentro do grupo em estudo. Além disso, sugere-se que indivíduos de $A$. diaperinus, ocorrendo no Paraná, possam ter se deslocado para os estados de Santa Catarina e Rio Grande do Sul.

O sucesso na obtenção de marcadores moleculares é dependente da qualidade do DNA obtido a partir dos tecidos do inseto. A técnica de extração que foi utilizada neste trabalho forneceu DNA com qualidade para analisar a variabilidade genética de A. diaperinus, utilizando-se cinco iniciadores de RAPD. Empregando-se cinco oligonucleotídios, foi possível demonstrar a variabilidade genética do grupo de forma rápida. Essa estratégia poderá ser usada quando houver a necessidade de se fazer uma análise de variabilidade genética de forma rápida, a baixos custos e com a utilização de poucos iniciadores para se identificar polimorfismos entre os indivíduos de uma amostra ou entre populações. 
Dessa forma, os marcadores moleculares obtidos por RAPD mostram-se úteis para um estudo preliminar da dinâmica de A. diaperinus ocorrendo na região sul do Brasil, assim como, para a caracterização de potenciais fragmentos de DNA para o desenvolvimento de marcadores moleculares mais sensíveis e eficientes para a identificação desse coleóptero em campo.

Uma futura aplicação poderá ser o desenvolvimento de um banco de marcadores moleculares para o monitoramento dessa espécie em campo. Para isso, várias populações deverão ser analisadas representando locais diferentes de ocorrência da espécie no Brasil.

\section{Conclusão}

O protocolo de extração que foi utilizado neste trabalho produziu DNA em quantidade e em qualidade para as reações de amplificação, usando os cinco oligonucleotídios de RAPD.

Os iniciadores de RAPD selecionados produziram perfis eletroforéticos para a identificação e a análise da variabilidade genética dos indivíduos de A. diaperinus.

Os iniciadores OPA-03 e OPA-13 produziram fragmentos isomórficos característicos para essa espécie de coleóptero.

O dendrograma indicou a organização das amostras de A. diaperinus em dois grupos principais, revelando uma elevada variabilidade genética.

A análise de AMOVA indicou que a maior fonte de variabilidade genética era proveniente de dentro das amostras analisadas. 


\section{Genetic variability of Alphitobius diaperinus revealed by RAPD molecular markers}

\section{Abstract}

The lesser mealworm, Alphitobius diaperinus (PANZER, 1797), is a cosmopolitan general stored-product pest of particular importance as a vector and competent reservoir of several poultry pathogens and parasites. This coleopteran inhabits poultry droppings and litter and is considered a significant pest in the poultry industry. In this work, individuals of $A$. diaperinus randomly collected from three localities of the Brazilian south region were submitted to molecular analysis by the RAPD technique. For this purpose a DNA extraction method was adapted and the decameric primers OPA-03, OPA-04, OPA-10, OPA-11 and OPA-13 were used. The DNA extraction method was suitable for the PCR amplification of DNA fragments for the analysis of the genetic variability of the lesser mealworm from three populations from the South of Brazil. A high genetic variability was detected among the populations analyzed in this study. It appears likely that the populations found in Santa Catarina and Rio Grande do Sul States may have originated in Parana.

Keyword: Alphitobius diaperinus. Coleoptera. RAPD. Molecular identification.

\section{Referências}

CHERNAKI, A. M; ALMEIDA, L. M. Exigências térmicas, período de desenvolvimento e sobrevivência de imaturos de Alphitobius diaperinus (Panzer) (Coleoptera: Tenebrionidae). Neotropical Entomology, v. 30, n. 3, p. 365-368, 2001. doi:10.1590/S1519-566X2001000300004.

CIAMPI, A. Y.; MAGALHÃES, M. T. Q. Análise da variabilidade genética de três espécies arbóreas utilizando marcador molecular RAPD. Comunicado Técnico, Brasília, v. 60, p. 8, 2001.

CRUZ, I. et. al. Manual de identificação de pragas da cultura do milho. Sete Lagoas: EMBRAPA/CNPMS, 1997. 
CRUZ, I.; VIANNA, P. A.; WAQUIL, J. M. Manejo das pragas iniciais de milho: o tratamento de sementes com inseticidas sistêmicos. Sete Lagoas: EMBRAPA/ CNPMS, 1999. (Circular Técnica, 31).

FERREIRA, M. E.; GRATTAPAGLIA, D. Introdução ao uso de marcadores moleculares em análise genética. Brasília: EMBRAPA-CENARGEN, 1998.

LESCHEN, R. A. B., STEELMAN, C. D. Alphitobius diaperinus (Coleoptera: Tenebrionidae) larva and adult mouthparts. Entomological News, Washington, v. 99, n. 4, p. 221-224, 1988.

MONNERAT, R. G. et. al. Variabilidade genética do parasitóide Diadegma sp. através de RAPD-PCR. Horticultura Brasileira, Campinas, v. 22, n.1, p. 90-92, 2004. doi:10.1590/S0102-05362004000100018.

MONTESBRAVO, E. P. Controle biológico de Spodoptera frugiperda Smith em milho. Disponível em: <http://codagea.edoags.gov.mx/ produce/SPODOPTE. htm>. Acesso em: 26 abr. 2001.

QUEIROZ, P. R. et al. C. Análise da variabilidade de uma população de Spodoptera frugiperda (J.E. SMITH, 1797) (Lepidoptera: Noctuidae) por meio de marcadores moleculares RAPD. Boletim de pesquisa e desenvolvimento, v. 75, p. 18, 2004.

ROHLF, F. J. NTSYS-pc: Numerical taxonomy and multivariate system. Version 2.9. New York: Applied Biostatistics, 1993.

WILLIAMS, J. G. K. et. al. DNA polymorphism amplified by arbitrary primers are useful as genetic markers. Nucleic Acids Research, Oxford, v. 18, n. 22, p. 65316535, 1990. doi:10.1093/nar/18.22.6531.

WALLACE, M. M. H.; WINKS, R. G.; VOESTERMANS, J. The use a beetle, Alphitobius diaperinus (Panzer) (Coleoptera: Tenibrionidae) for the biological control of poultry dung in high-rise layer houses. The Journal of the Australian Institute of Agricultural Science, Curtin, v. 51, n. 3, p. 214-219, 1985.

VITTORI, J. et. al. Alphitobius diaperinus spp como veiculador de Clostridium perfringens em granjas avícolas do interior paulista - Brasil. Ciencia Rural, Santa Maris, RS, v. 37, n. 3, p. 894-896, 2007. doi:10.1590/S0103-84782007000300048. 